\title{
CESPUC
}

\section{REVISÃO, EDIÇÃO E PREPARAÇÃO DE TEXTOS: O DESAFIO PROFISSIONAL DE NOVOS CENÁRIOS DE ATUAÇÃO}

Ev'Ângela Batista Rodrigues de Barros* Daniella Lopes Dias Rodrigues Ignácio**

* Professora do Departamento de Letras da PUC Minas. Coordenadora Adjunta do CESPUC. Editora da Revista do ICH e da Revista Conecte-se! (Proex).

** Professora do Departamento e do Programa de Pós-graudação em Letras PUC Minas. 
Nos últimos quinze anos, temos assistido a um crescimento no interesse pela institucionalização da profissão de revisor(a) de textos (o que se revela, entre outros fatos, por meio da criação de uma associação profissional específica, a Associação Brasileira de Revisores de Textos (ABRT), em 2015, o que realoca o olhar sobre quem é o indivíduo que se debruça sobre o texto alheio, dotado de um saber de múltiplas dimensões - textuais, de forma mais ampla; linguísticas, sob a ótica do conhecimento do sistema, da norma; enciclopédicas ou pragmáticas, do ponto de vista de um sujeito que vive e atua num cenário sociopolítico, histórico, discursivo etc. e que o afeta e é por ele afetado). Embora todo esse processo de reconhecimento da prática profissional de revisão de textos tenha decorrido da existência e consolidação dos cursos de bacharelado em Letras e aos de pós-graduação lato sensu em revisão, ainda há muito que se discutir sobre o que se entende por intervenção textual, bem como sobre os limites (inclusive éticos) desse fazer, que envolve um processo original de escritura e um secundário, de re-visão, mas que se torna tão impregnado ao texto primeiro que, às vezes, torna-se difícil o deslinde das camadas constitutivas.

Segundo Heurley $(2010)^{1}$, a revisão de textos é um domínio de pesquisa legítimo desde a publicação do modelo de Hayes e Flower (1980), que conferiu à revisão o estatuto de subprocesso do processo de escritura. No Brasil, na década de 1980, a publicação da obra de Maria Teresa Serafini, Como escrever textos, estabelece a revisão como uma das etapas da produção de textos, embora se tenha dado pouca atenção ao capítulo destinado à intervenção textual propriamente, diante do grande número de trabalhos que formavam o corpus a partir do qual se propuseram a discutir os tipos de correção ${ }^{2}$ identificados pela autora na correção de redações. Já na década de 1990, o livro No mundo da escrita, de Mary Kato, discute o modelo de escrita de Hayes e Flower (1980) que, como dissemos, estabelece a revisão como uma das etapas da escrita.

É na década de 2000 que alguns pesquisadores brasileiros (para citar alguns, confira, por exemplo, Oliveira (2006); Alves (2007); Muniz Jr. (2009); Ribeiro (2009, 2016); Perpétua; Guimarães (2010); Mourão (2010); Rodrigues (2010); Hermont; Assumpção (2010); Costa; Rodrigues; Pena (2011); Passos; Santos (2011); Salgado (2013, 2016)) se propuseram a refletir sobre a prática de revisão textual a partir de uma perspectiva discursiva. Apesar de todo esforço desses autores, as concepções de língua e de texto equivocadas que ainda vigoram em manuais que orientam a prática do revisor - sem falar no poder de prestigiosos profissionais da mídia que (des)orientam o uso da língua - contribuem para que a prática de revisão de textos ainda venha sendo calcada, muitas vezes e exclusivamente, na gramática normativa, desconsiderando a natureza discursiva do funcionamento da linguagem.

As obras que enfocam aspectos gramaticais sob uma perspectiva normativista, sejam elas gramáticas ou obras congêneres - por exemplo, 1001 dicas de Português. Guia prático do Português -, que muitas vezes são vistas como referência para o trabalho do revisor, "assumem

$1 \mathrm{O}$ texto aqui mencionado é uma tradução do francês, publicada na revista Scripta, n. 26, de um artigo da revista Langage inteiramente dedicado à revisão de textos: Langages, 40e année, ${ }^{\circ} 164$. 2006. La révision de texte. Méthodes, outils et processus, sous la direction de Sabine Pétillon et Franck Ganier.

2 A correção indicativa consiste em marcar junto à margem as palavras, frases e períodos inteiros que apresentam erros ou são poucos claros [...]; a correção consiste em reescrever todos os erros, reescrevendo palavras, frases e períodos inteiros [...]; a correção classificatória consiste na identificação não ambígua dos erros através de uma classificação." (SERAFINI, 1989, p.113-114). 


\section{C \\ 2O SEMESTRE DE $2017-$ N. 31}

Ev'âAngela B. R. de Barros e Daniella Lopes D. Rodrigues Ignacio

a variedade escrita literária a única digna de ser estudada, ensinada e praticada" (BAGNO, 2000). Nesse quesito, são tão restritivas e ignorantes das variações dialetais do português brasileiro como o são as gramáticas normativas.

E vale destacar essa situação controversa entre o que é norma (normal) x norma (normativo), pois é cena corriqueira ouvir de alunos, sejam da educação básica, do ensino superior ou mesmo da pós-graduação, sempre as perguntas: É certo escrever assim? Qual a forma correta, $\mathrm{X}$ ou $\mathrm{Y}$ ? Ora, se se entende que a existência dos textos se dá a partir de suas contingências contextuais, não é possível predefinir uma única forma correta. "Para um linguista, o conceito de certo e errado não tem sentido (seria como um botânico achar que uma planta está errada). Para ele, a questão é quais são as regras em cada caso” (POSSENTI, 2011) - acrescentamos, em cada contexto de uso da língua; e no caso específico do revisor, em cada suporte ou veículo de circulação daquele exemplar que se encontra em revisão.

Reverberando posicionamento crítico de grande discussão entre os que pesquisam as práticas de produção e tratamento de textos, Dias (2015) afirma que é preciso assumir a revisão textual como uma prática discursiva, cujas intervenções ou ausências geram efeitos de sentidos. Sob esse ponto de vista, a importância do revisor na cadeia editorial - de qualquer texto - não incide apenas nas tarefas / atribuições desse profissional em cada obra e/ou gênero discursivo, mas na sua intervenção como ator social (CHARTIER, 2002). Compreender a revisão dessa perspectiva significa ver o texto em toda a sua materialidade linguística e, concomitantemente, em sua materialidade discursiva. Assim, o revisor, mais do que conceber a língua escrita do ponto de vista da norma, vincula a dimensão propriamente linguística à dimensão textual-pragmática-discursiva. Tal proposta envolve focalizar as questões relativas à ortografia, à pontuação, às escolhas lexicais, à estruturação sintática e às regras de edição atreladas à dimensão textual-pragmática-discursiva. Esse ponto de vista prioriza, fundamentalmente, as estratégias do dizer em relação às condições de produção do discurso.

Ademais, advogamos pela necessidade de tomar a palavra "revisão" no plural, pois ela é, por essência, realizada em várias situações comunicativas, desde as mais até as menos institucionalizadas. Esquematicamente, a atividade de revisão de textos pode ser representada do seguinte modo: 


\section{CESPUC}

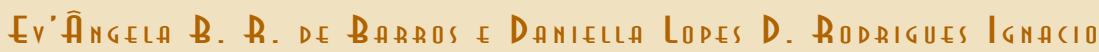

Figura 1 - Etapas da Revisão de Textos

Tevisão de
textos

Fonte: Elaboração de Dias, 2017.

O objetivo desse esquema é demonstrar que, a depender da situação em que a revisão de textos se realiza, várias são as possibilidades de intervenção. Constituem essa situação o papel social do revisor (profissional, aprendiz, o próprio escritor do texto), a modalidade em que ela se realiza (informatizada, manuscrita), os níveis de intervenção (textos inteiros, livros ou unidades frásticas) e o lugar social em que a revisão se realiza (escola, editoras).

É sob essa perspectiva que apresentamos o volume 31 do Cadernos CESPUC, dedicado à "Revisão, edição e preparação de textos", o qual organizamos, de acordo com as temáticas prevalentes nos artigos aprovados, em três seções:

a) na primeira, concentram-se três artigos que trazem à tona questões referentes à revisão textual no âmbito institucional - dotado de idiossincrasias e formalidades, o que deixa entrever uma estrutura mais formulaica, ainda assim, sob uma análise acurada revela forças pragmáticodiscursivas que se inscrevem nas relações dialógicas instauradas;

b) na seção seguinte, encontram-se três artigos que tratam dos desafios representados pelas novas formas de circulação textual, as novas mídias, para a prática do revisor - seja em traduções de legendas de séries, seja em verbetes digitais, o revisor encontra novo lócus de atuação, com suas especificidades e vai desbravando áreas e inaugurando práticas;

c) na terceira seção, três artigos discutem aspectos de ordem linguística, presentes em textos basicamente das esferas acadêmica e jornalística, que refletem opções discursivas e de expressividade, disponíveis ao autor, no momento da produção, e que se constituem em desafios ao profissional da revisão, quando de sua incursão nas especificidades dos gêneros de tais esferas - normatização $x$ discursividade; escolhas por maiúsculas $x$ minúsculas; o jogo entre verbal $x$ verbo-visual. Como as autoras afirmam, nada é aleatório, há sempre uma intencionalidade a ser detectada. 


\section{Chane

Passemos a um olhar mais próximo desse rico acervo constitutivo do presente volume.

No primeiro artigo, "O manual de redação institucional como facilitador do trabalho de revisão: uma análise dos documentos oficiais de padronização da escrita de institutos federais de ensino", os autores Tamires Ramalho de Sousa, Luciana Cabral Farias e Cristiano Florentino discutem o valor de manuais de padronização da escrita ou documentos normatizadores similares adotados em instituições federais de ensino superior. Facilitadores ou complicadores para a atuação do revisor? Qual o conteúdo abordado e em que pressupostos sua elaboração se funda? Questões cujas respostas se descortinam a partir da análise de dados disponíveis nos sites dos Institutos Federais de Ensino sobre a existência ou não de tais manuais de estilo, seguida por cuidadosa análise documental, bem como por entrevistas com revisores de texto dos institutos que dispõem de manuais. Os resultados evidenciam, entre outros aspectos, os consensos quanto a conteúdos e práticas, as divergências entre posicionamentos quanto ao valor desses materiais, bem como o desconhecimento de alguns dos revisores sobre materiais normatizadores das instituições em que trabalham.

No segundo artigo, "Marcas de pessoalidade em documentos oficiais dos municípios mineiros dirigidos ao TCEMG: possível atuação-orientação do profissional revisor", Romero de Assis Caixeta, depois de proceder a acurado exame de múltiplas ocorrências em documentos com que lida cotidianamente, aponta como se materializam as ocorrências de marcas de pessoalidade em exemplares dos diferentes gêneros oficiais encaminhados ao Tribunal de Contas do Estado de Minas pelos responsáveis dos órgãos da Administração Pública Direta ou Indireta dos municípios mineiros. A partir da constatação, propõe algumas reflexões acerca da possível atuação do profissional revisor de texto no âmbito do órgão público remetente, com vistas ao aprimoramento da redação final desses documentos.

Por fim, em "Manual de Redação da Presidência da República: entre princípios e mitos", Paulo Anízio Martins de Souza aborda a existência de possíveis mitos linguísticos no MRPR - "entendidos como quaisquer enunciados de natureza gramatical sujeitos a questionamentos, por ser cabível tomá-los como materialização de ideias inconsistentes sobre a língua, sobre sua variedade de maior prestígio e sobre o texto". A análise baseou-se no cotejamento entre o posicionamento de autores da abordagem funcional e pragmática, com artigos da Constituição Federal no qual se baseia o manual de redação analisado, levando-se em consideração fatores sociais e geográficos, inerentes às peculiaridades territoriais e populacionais do Brasil. Conclui o autor que operam três mitos: "Mito da homogeneidade do destinatário", "Mito do padrão culto de linguagem" e "Mito da clareza do texto oficial", os quais são devidamente discutidos. Relevando a validade da norma padrão, sem negligenciar as condições imprescindíveis de textualidade, Souza questiona aspectos e estratégias que promovem (ou não) a eficácia dessa norma em certos atos e documentos públicos.

Introduzindo a seção que contempla a temática seguinte, o quarto artigo, "A tradução do humor nas legendas de The Office", de Nathalia Cristina de Freitas Campos analisa expedientes que deveriam retratar, na tradução, traços de humor do texto original. Por meio da análise das legendas em português da série The Office, discute como a revisão pode ajudar para que a legenda capte de forma mais próxima possível o contexto de cada cena. Mais do que uma 
análise linguística, trata-se de um trabalho que captura a complexidade da tradução e da revisão de textos traduzidos, permeada por um olhar sobre a cultura do povo da língua fonte em confronto com aspectos culturais dos falantes da língua alvo (no caso, o Português), num veículo premido pela pressão do tempo - dizer muito, de forma adequada ao contexto, de forma sintética: eis os condicionantes para o bom trabalho do tradutor e do revisor, nesse caso. Para apoiar sua análise, Campos disseca cenas específicas, observando se as legendas conseguem ou não transmitir convenientemente a mensagem para o telespectador, em um curto espaço de tempo, e sugere intervenções que poderiam manter a fidelidade de sentidos entre a tradução e o diálogo original.

Com o quinto artigo, "A revisão de textos na Wikipédia lusófona", de Moema Ungarelli, constrói-se um retrato da atual situação do trabalho de revisão (ortográfica, gramatical, de estilo) dos textos da Wikipédia Lusófona e das ferramentas hoje disponíveis para o cumprimento desta tarefa. Mostrando os bastidores da constituição da equipe de revisores, as orientações teóricas e capacitações para esses profissionais redatores / revisores, a autora objetiva discutir novos procedimentos para agilizar o processo de revisão e minimizar e a ocorrência de artigos publicados com erros de redação. Para tanto, lança mão da pesquisa exploratória em livros, estudos e trabalhos acadêmicos sobre os conceitos de inteligência coletiva, $W e b 2.0$, produção colaborativa em ambientes digitais e sobre a Wikipédia; em seguida, lança-se à análise de dados gerados pela observação das páginas internas da Wikipédia e de contatos mantidos com seus colaboradores. Ao final, apresenta e discute uma proposta de criação de um Grupo de Trabalho voltado à organização do processo de revisão gramatical dos verbetes.

Fechando esta seção, o sexto artigo, "Desafios do revisor: o uso de tecnologias em revisão e tradução", de Flávia Maurício da Rocha Fontes, graduanda do Bacharelado em Letras, dialoga com os precedentes, ao discutir algumas práticas de revisão tomando como cenário o âmbito tecnológico. Apresenta as funções e as limitações de revisores automáticos e como estes influenciam o papel do revisor profissional. A partir de breve análise de textos presentes no cotidiano (anúncios publicitários, poemas, etc.), propõe uma discussão sobre as limitações de correções feitas pelos programas de computador. No geral, seu texto nos conclama a uma reflexão sobre as competências necessárias ao revisor profissional que se sabe responsável por intervenções não apenas linguístico-gramaticais, mas também de outras naturezas, como adequação às normas de publicação, contexto de criação do texto, gênero e textualidade. Firmemente ancorada na perspectiva sociointeracionista de texto, cujo cerne se encontra no caráter sociocomunicativo da produção e revisão textuais, algumas relevantes estratégias discursivas do trabalho do revisor são aqui explicitadas.

Na terceira seção, temos o sétimo artigo, "O uso de iniciais maiúsculas e minúsculas: estudo comparativo entre o Manual de Redação e Estilo do jornal o Estado de S. Paulo e o Manual de Redação do jornal Folha de S. Paulo", em que Marina Carneiro de Rezende Vilhena, partindo da apresentação de referencial teórico sobre formatação de estilo jornalístico e da padronização de elementos textual-discursivos, realiza um estudo comparativo entre o manual de $\mathrm{O}$ Estado de S. Paulo e o manual da Folha de S. Paulo, no que se refere ao uso de iniciais maiúsculas e minúsculas nas diversas situações de emprego das palavras. Analisando a premissa 


\section{Clemer

da uniformização da escrita jornalística, a autora encontrou muitas convergências e algumas divergências: tomando como corpus de pesquisa fragmentos de matérias jornalísticas publicadas nesses jornais, verificou "o fiel cumprimento do revisor às normas estipuladas nos dois manuais, sobressaindo, assim, a presença efetiva da padronização no texto jornalístico". Em cotejamento com outros materiais oficiais (como Acordo Ortográfico de 1990 e gramáticas normativas), foi possível constatar que os citados manuais expandem a aplicação do uso de iniciais maiúsculas e minúsculas, apresentando mais opções de emprego das palavras. Conclui Vilhena que "os manuais, como instrumentos tecnológicos, são uma das fontes de produção do conhecimento sobre a história da língua, que complementam a construção e disseminação da norma culta, já que podem substituir, em casos específicos, as fontes oficiais, principalmente na consulta de dúvidas".

O oitavo artigo, da graduanda em Letras, Thatiane Cristina da Silva Marques, discute "A relação da normalização em notas de rodapé e a discursividade em textos acadêmico-científicos". Com o intuito de propor reflexões sobre o valor discursivo que subjaz ao emprego das normas de padronização apresentadas em textos acadêmico-científicos, enfoca tanto as prescrições de uso de notas de rodapé e suas funções no texto quanto situações que se espraiam para além do que apregoa a ABNT - por meio da análise de alguns exemplos de notas de rodapé, discute possíveis limites e adequações desse elemento textual. Ao final, defende a ideia de que o revisor não deve se restringir às questões linguísticas e de padronização, mas deve priorizar o discurso utilizado e seus efeitos de sentidos.

Fechando o volume, Eliene Vieira de Santana discute, em "Discursos textuais e gêneros híbridos: desafios para o revisor de textos.", aspectos gráficos e verbo-visuais que, constitutivos da estrutura de textos do âmbito jornalístico, impõem novas demandas ao profissional que atua no mercado de trabalho. Partindo do aporte fornecido pela teoria de Gêneros Discursivos como respaldo ao trabalho do revisor de textos para o desempenho efetivo de suas funções, sua pesquisa bibliográfica, qualitativa, ressalta a importância do conhecimento do fenômeno da hibridização - que se realiza não na estrutura textual, mas no âmbito da discursividade - para o profissional de revisão de textos na execução de seu trabalho cotidiano. Como aplicação, apresenta breve análise de um texto jornalístico institucional publicado no DOM (Diário Oficial do Município) de Belo Horizonte e de uma publicação do Informativo do Sindicato dos Trabalhadores em Educação da Rede Municipal de Belo Horizonte - SindRede - sobre o mesmo tema. Evidencia o caráter híbrido do gênero - reportagem ou publicidade institucional? - e os efeitos da paródia como crítica, no segundo suporte.

Como se pode constatar, o ofício de revisor de textos tem assumido, cada vez mais, nuances até recentemente impensadas - novos gêneros, híbridos ou não, novas mídias, novas relações interpessoais em diferentes instâncias (inclusive as denominadas "oficiais"), entre outros aspectos - vêm demandando a esse profissional a agregação de variadas competências que não apenas as tradicionalmente vinculadas à profissão: para além das já tradicionais - o conhecimento linguístico, o conhecimento genérico / textual, o conhecimento enciclopédico -, requerem-se atualmente competências tecnológicas, competências em idiomas (que permitam avaliar a efetividade da tradução em relação ao texto fonte), competências interpessoais (como 


\section{CESPUC}

Ev'âAngela B. R. de Barros e Damiella Lopes D. Rodrigues Ignacio

a de trabalhar em equipe) são algumas delas...

Maior profissionalização do ofício de revisor, acreditamos, é um bom caminho para o reconhecimento do caráter não voluntarista deste relevante trabalho, que descortina boas perspectivas para os egressos da área de Letras e Comunicação Social, mas não apenas para essas áreas.

\section{Referências}

ALVES, Maria da Penha Casado. Um olhar dialógico sobre a atividade de revisão de textos escritos: entrelaçando dizeres e fazeres. $172 \mathrm{f}$. Tese (Doutorado em Estudos da Linguagem). Universidade Federal do Rio Grande do Norte, Natal, 2007.

BAGNO, Marcos. Dramática da língua portuguesa: tradição gramatical, mídia e exclusão social. São Paulo: Loyola, 2000.

CHARTIER, Roger. Do palco à página. Publicar teatro e ler romances na época moderna séculos XVI-XVIII. Tradução de Bruno Feitler. Rio de Janeiro: Casa da Palavra, 2002.

COSTA, Roger Vinícius; RODRIGUES, Daniella Lopes; PENA, Daniela Paula. Dificuldades no trabalho do revisor de textos: possíveis contribuições da linguística. Revista Philologus, ano 17, n. 51, set./dez. 2011 - Suplemento. Rio de Janeiro: CiFEFiL, 2011. p. 74. Disponível em: http://www.filologia.org.br/revista/51 supl/05.pdf. Acesso em: ago. 2015.

DIAS, Daniella Lopes. Para além da normalização: aspectos discursivos das normas de padronização. SCRIPTA, Belo Horizonte, v. 19, n. 36, p. 357-368, 1º sem. 2015.

HERMONT, Arabie Bezri.; ASSUMPÇÃO, Solange Bonomo. Educação a distância: como revisar os materiais didáticos. Scripta, Belo Horizonte, v. 14, n. 26, p. 179-194, $1^{\circ}$ sem. 2010.

HEURLEY, Laurent. La revisión de texte: l'approche de la psychologie cognitive. Langages, Paris, n. 164, p. 10-25, 2006. Disponível

MOURÃO, E. A hipercorreção na escrita formal: dilemas do revisor de textos. Scripta, Belo Horizonte, v. 14, n. 26, p. 195-204, 2010.

MUNIZ JÚNIOR, José de Souza. A intervenção textual como atividade discursiva: considerações sobre o laço social da linguagem no trabalho de edição, preparação e revisão de textos. (2009). Disponível em: < http://www.intercom.org.br/papers/ nacionais/2009/ resumos/R4-1079-1.pdf>. Acesso em: 19 mar. 2015.

OLIVEIRA, Risoleide Rosa Freire de. O papel mediador do revisor de textos: dos aspectos discursivos aos aspectos notacionais. XXI Jornada Nacional de Estudos Linguísticos. João Pessoa: s. ed., 2006. p. 2483-2492.

PASSOS, João Augusto de Oliveira; SANTOS, Maria Lino dos. Leituras, revisão textual e o revisor. Revista Anápolis Digital, n. 7, 2011. Disponível em: http://www.anapolis.go.gov.br/ 


\section{CESPUC \\ 20 SEMESTRE DE $2017-$ N. 31}

Ev' $\hat{A n g e l a}_{\text {B. }}$ B. R. de Barros e Damiella Lopes D. Rodrigues Igmacio

revistaanapolisdigital/wp-content/uploads/2011/07/LEITURAS-REVISAO-TEXTUAL-E-OREVISOR.pdf. Acesso em: ago. 2015;

PERPÉTUA, Elzira Divina; GUIMARÃES, Raquel Beatriz Junqueira. A revisão do texto literário: um trabalho de memória. Scripta, Belo Horizonte, v. 14, n. 26, p. 195-204, 2010.

POSSENTI, Sirio. Língua, que bicho é esse? São Paulo: Carta Capital, 2011. Disponível em: https://www.cartacapital.com.br/educacao/carta-fundamental-arquivo/lingua-que-bicho-eesse Acesso em: 09 set. 2017.

RIBEIRO, Ana Elisa. Revisão de textos e "diálogo" com o autor: abordagens profissionais do processo de produção e edição textual. In: CONGRESSO BRASILEIRO DE CIÊNCIAS DA COMUNICAÇÃO, 32, 2009, Curitiba. Anais... Curitiba: Intercom, 2009. Disponível em: http://www.intercom.org.br/papers/nacionais/2009/resumos/R4-2050-1.pdf. Acesso em: 20 jul. 2012.

RIBEIRO, Ana Elisa. Em Busca do Texto Perfeito: questões Contemporâneas de Edição, Preparação e Revisão Textual. Divinópolis, MG: Artigo A, 2016.

SALGADO, Luciana Salazar. Ritos genéticos editoriais: uma abordagem discursiva da edição de textos. Rev. Inst. Estud. Bras., São Paulo, n. 57, dez. 2013. Disponível em: < http://www. scielo.br/scielo.php?script $=$ sci_arttext\&pid $=$ S00203874201300020001 1\&lng $=$ en\&nrm $=\mathrm{i}$ so >. Acesso em: 19 mar. 2017.

SALGADO, Luciana. Quem Mexeu no Meu Texto: Questões Contemporâneas de Edição, Preparação e Revisão Textual. Divinópolis, MG: Artigo A, 2016.

SERAFINI, Maria Teresa. Como escrever textos. 2. ed. Rio de Janeiro: Globo, 1992. 